\title{
KNOWLEDGE MANAGEMENT FOR HIGHER EDUCATION
}

\author{
Sanjiv Sharma ${ }^{1} \&$ Dr. Parveen Kumar $^{2}$
}

Abstract- Making knowledge usable for many an organization and to share the knowledge is the purpose of Knowledge Management (KM). The business of knowledge is all pervading in institutions of higher education where the responsibility of creation, sharing, transferring, storing, distributing, re-using and learning is being taken up by them. If the KM is well preserved using good technology, the intellectual output of an academic organization will benefit greatly from it. A Learning Organization (LO) imbibes a culture that not only bolsters learning but also the innovations brought about by individuals as well as organizations.

Keywords - Knowledge Management (KM), Higher education institutions, Learning Organization (LO).

\section{INTRODUCTION}

An important source of value creation in an organization that needs to be precariously managed is Knowledge [1].The information that is created is captured in different documents and also databases. It is made dispensable when the researchers who use information technology and retrieval systems search for the same.

Knowledge is of two types: Explicit Knowledge and Tacit Knowledge

Explicit Knowledge - The kind of knowledge that can be expressed, communicated, recorded and documented (in formal language) is explicit knowledge. This can be published and made dispensable for primary and secondary information sources. It includes know how that is packaged, transferrable and available. There are various ways in which it can be articulated, presented and codified in forms such as facts, rules, reports, blog posts, email, words, numbers, printed books/journals, digital assets, policies. They can be shared without the discussion being necessary. It can include the past events and can be transferrable in both formal and systematic language.

Tacit knowledge - The knowledge that is carried by a person is tacit knowledge. This is a part and the parcel of the minds and is embedded in the heads of the organization/researcher/ institution etc. This is unique to a person that comprises perceptions, expertise, techniques, skills, insights. This knowledge is purely personal and is hence not communicated in any written form; It is not specific to any field, tough to capture, to share verbally and transfer to the society. Since it is specific to context, we cannot formalize or express. This kind of knowledge is classified, not easily shared and preserved by many as a trade secret. Its features are quite distinct from those of the explicit know-how. Technologies such as discovery, acquisition, sharing, distribution, application and preservation in repositories and libraries are important to facilitate KM activities [2].

A novel emerging field in the academic environs is KM. These form an important part of many upcoming conferences and seminars both at National and international levels. Several international universities are getting involved in KM related activities like research. Because of the necessity of disclosing intellectual know-how for sharing the experiences, KM has become significant in the field of education. Hence, its potential in the educational sector is unparalleled. Knowledge spawns from past events. Humans are the main sources of knowledge as they make efforts in innovations, research and educational activities in different areas. While explicit knowledge can be easily disseminated, tacit knowledge is tough to compile as it is very personal to an individual.

An organization can be transformed to a new level of efficiency, effectiveness and its scope of operation can be expanded using advanced data and technology by means of KM. This enhances he productivity of the users. Continually unraveling the organizational tacit knowledge is KM. It helps develop know how, solve problems and make decisions. There is no field that does not encompass KM e.g. Industries both private and public, international charities, educational sectors etc. As a discipline, KM should strive in achieving the goals in a better fashion and many a time exceeding them. Hence, merely garnering more knowledge is not the sole purpose of KM. It extends to creation, consolidation, transfer and knowledge application with a defined purpose. Re-inventing the wheel, in which many organizations are involved today, is expensive and non-productive. But the benefits will be shown by systematic knowledge re-use. Our tendency to repeat mistakes will drastically come down with effective KM.

Supporting organizational processes [3] and practices, building an environment conducive to knowledge creation and sharing and enabling collaboration and communication within the organization is the purpose of KM. Going beyond technological systems, the KM tools are virtual spaces wherein the conversion takes place between tacit and explicit knowledge. The knowledge tools bring few benefits to knowledge management in general and HEI in particularly, if there is no strategy and

\footnotetext{
${ }^{1}$ Research Scholar, NIMS University, Jaipur, Rajasthan, India

${ }^{2}$ Professor, (CSE), Computer Science and Engineering, NIMS University, Jaipur, Rajasthan, India
} 
organizational culture which is based on continuous collaboration, learning and sharing. Knowledge repositories, Workflow tools, learning system, knowledge maps, web 2.0 applications and ontologies, corporate portal and Collaboration tools are some KM learning tools.

An organization is focused as an entity by the LO. An ideal organizational vision which could help organizations to cope with and even lead environmental change by reinforcing learning activities [4]- this is the definition of a learning organization. An LO is comprised in such a manner that, it itself created information, scans for the information in the environment and motivates people to share knowledge among the team members. The strategic leadership of an organization that formulate the structure and the vision of an enterprise must guide this process. Learning must be considered as real work and employees must eek out time for learning. In an LO, each aspect of knowledge must be integrated with the work they do. The knowledge sharing and distribution should be a part of the organizational culture.

Thus, LO is an entity of an entire organization which in turn is the entity of the whole world. As a part of the system, the organization must communicate with other sub systems and manage factors like competitors and customers that are external to an organization. This is extremely important for survival. Since KM is performed in a sub-system, its focus is more on internal organizational factors. However, the KM literature that mentions external factors manages them implicitly, considering the factors that the organization has to manage. The efficiency of KM depends on internal factors. These are discussed in terms of constraints. Thus, meeting internal demands is the focus when LO [5] considers the internal factors. Achieving the demands of members in an organization means meeting the internal demands of individuals as organization is made up of individuals. Relative to an organization, every member has his or her own image. The practice of every organization emerges from these images; as the conditions change, the members remake them. Each individual is a subsystem in KM. Considering this perspective, it is strange that system's thinking to our knowledge not explicit is discussed in this domain. But, when discussing LO, to have system's thinking, means this approach also can be used for KM.

The stored knowledge is referred to as organizational memory. It aims to achieve sharing and re-use of knowledge. The type of KM that gathers knowledge outside people corresponds to the organizational memory. IT is a prerequisite for effective $\mathrm{KM}$ [6], in the perspective of knowledge storage, dissemination and sharing. Hence, we observe that there is a strong correlation between organizational memory and technical know-how. In both these, knowledge is considered as a product, exactly in the lines of KM. The input to LO or the outcome from LO is knowledge. A process that transforms knowledge is regarded as LO by KM. OL is a collective cognitive procedure and also good at organizational learning. Organizational memory is not explicitly discussed in the LO literature. Organizational knowledge is discussed wherein; a part is the organizational memory. The LO is a step above KM as it concentrated on the higher level. It is more about fostering a culture for learning and building structures that support learning. An LO focuses on learning structures in general, where IT is only a part, although, use of IT supports learning structures. Hence, it is natural that LO does not contain a technical focus. Thus IT is taken for granted, more or less, by the LO, as it happens in the case of telephones, mails, documents and so on.

\section{LITERATURE SURVEY}

The results of a recent project for development of a Knowledge Management System (KMS) in university environment were presented by Laal [7]. A brief introduction into the design approaches and the KMS understanding is provided firstly. Next, the approach that is followed by the authors is shown. Lastly, the analysis of the feedback taken by the users post the pilot testing of the KMS is made.

A framework that enhances the collaboration in institutions of higher education and enables knowledge sharing was presented by Pinto [8]. The paper discusses the knowledge management concept in institutions of higher education. It presents systematic knowledge tools and practices that link knowledge to people like teachers, researchers, students, secretarial staff etc. It also discusses the sharing of knowledge across many key processes such as learning process, research process, alumni and student services, strategic planning and management, administrative services and processes. The paper presents a framework that aims to improvise knowledge practices, processes that enable knowledge sharing and discovery that are characteristic to a higher education institution.

The requirement for an organization to become a $\mathrm{LO}$ grows by the day $\mathrm{KM}$ is required by $\mathrm{LO}$ and is also dependent on it. It is difficult to determining what comes first just like the chicken and egg scenario. As each is dependent on the other for success, this question cannot be answered. Literature says that despite the dependency, both LO and KM must be emphasized upon. This was addressed by Aggestam [5]. LO is mapped to KM and the conceptual model of LO and KM is presented in a holistic manner. This model, in future, presents a framework for making guidelines for the introduction of LO and KM.

How knowledge is managed and used in educational institutions was analyzed by Nawaz\& Gomes [9]. Strategic Knowledge (SK) and Innovations Knowledge (IK) are the two models that have been discussed in detail.

According to Strategic Knowledge, tacit and explicit are the basic sources of knowledge. Innovations knowledge states that strategic knowledge is the basic source. Keeping in view, the available literature and the currently practicing models, these two conceptual models have been designed. Finally these two conceptual models are compared. This is done keeping in mind the usability of KM in the institutions of higher learning. How this KM adds value to a higher educational institution has been emphasized in this paper.

Appraising the level of organizational learning of the agricultural and natural recourses campus (ANRC) of University of Tehran as the oldest higher education institute in Iran was studied by Veisi [10]. For quantifying managerial practices at 
campus relative to the integral components of organizational learning, a questionnaire was developed as the survey instrument. The subjective opinions of faculty members in ANRC of University of Tehran were obtained by the survey.120 members from the faculty were randomly drawn from the population selected. Using frequencies, percentages, and mean, data was analyzed. According to the results, more than $90 \%$ of the faculty members had a view of meeting institutions of higher learning of agriculture as a LO. They also accorded with the component of the systems thinking which was the most important dimension of LO. Many of the issues in research that bridge the gap that currently exists between the theory building requirements and testing for addressing the various challenges in using ICT for enhancing KM in higher education were identified by Omona et al [11].

Information and Communications technology or ICT is the newly emerging field that has changed the world. ICTs will soon become an indispensable part of every person. For studying information technology adoption in different parts of the world, various models of diffusion, technology and adoption have been previously adopted. Identifying a feasible model for adopting technology in Jordan and determining factors that influence the adoption of technology have been identified by Khasawneh \& Ibrahim [12]. There is a scarcity of studies in the academic literature or in the trade press relating to the experience of other developed and developing country, though some studies conducted in industrial nations do exist. The know-how of the adoption and diffusion of ICT by focusing attention on an area hitherto neglected or overlooked, will be enhanced, supposedly, by the findings of this study. An introduction of a PhD thesis in "The Adoption of ICT in developing countries" by taking Jordan as case study will be presented in this paper. Some of the existing models are discussed in the first part. This is followed by the discussion models of the ones related to the study in developing nations such as Jordan.

Based on Common Wealth Magazine's Top 1000 manufacturers and Top 100 financial firms in 2007, Liao\& Wu [13] selected samples by mails. They also conducted a questionnaire survey. A total of 327 replies were received. The relationship among knowledge management, as well as organizational learning and organizational innovation utilizing structural equation modeling has been analyzed by the research. It has been shown by the research that organizational learning is the mediating variable between knowledge management and organizational innovation. Like a system, an important input is the knowledge management; a key process is organizational learning and a critical output is the organizational innovation.

\section{METHODOLOGY}

\subsection{Knowledge Management (KM) Processes}

Four processes of knowledge management [14]:

1. Knowledge gathering or acquisition

2. Knowledge storage and organization

3. Knowledge distribution

4. Knowledge application

Knowledge Acquisition or Gathering - This includes knowing what we know, getting knowledge from external world, and also spawning new knowledge. There is a process called as knowledge identification before gathering and acquiring knowledge. Here, we need to identify the information about the know-how that is possessed by the organization and the knowledge it requires to become more competitive. Thus, an organization which identifies itself as the LO alone is capable to managing its know-how.

Knowledge Storage and Organization - It is necessary to organize the knowledge that has been obtained, collected and spawned in the form of a database. This enables the access to it anytime as well as its utilization. This requires indexing skills and application of technology with the adequate infrastructure.

Knowledge Sharing or Distribution - For the knowledge to become usable, it has to be shared and disseminated in a society or an organization. The aim of knowledge sharing is to prevent the disappearance of knowledge from an organization in case of attrition.

Knowledge Application - Once shared, the knowledge must be appropriately applied for addition of new knowledge to the data bases and for gaining better returns. The entire process goes down the drain if the knowledge that is created, gained, shared and stored is not applied properly. Hence communication of the KM process is a must for proper knowledge application.

\subsection{Knowledge Management (KM) in Higher Education -}

There are various ways in which KM [15] enriches higher educational systems: Better student retention, better graduation rates, cost effective technology use, greater enrollment, transformation of existing transaction system for providing information and competing in an environment wherein the student needs can be met anytime and anywhere. It is required by the complex knowledge society to be evolving constantly, analyzing, innovating, investigating, predicting and responding to threats and opportunities. Knowledge is stored, accessed and delivered uniquely by all organization. The difference lies in the manner that they utilize the knowledge capital for adding value to their products or services. Unrelated activities of knowledge have to be avoided by the universities. In a knowledge based society, their staff has to respond and recognize the changing role. They need to explicitly and consciously manage the processed that are concerned with the knowledge creation. The value of the knowledge capital as an evolving entity must be recognized in a global marketplace for higher education. 
The following characteristic to the higher education institutions have been formulated by the knowledge workers:

- Good thinking, managerial skills and analytical power skills are demonstrated by the knowledge workers. This translates into innovative and creativity skills.

- Continuous learning for creating awareness about the demand of future changing environment is performed by the knowledge workers. These strategies that an organization can sustain are implemented by them.

- They believe in team spirit, collaborations, cooperation and coordination and built trust among the workers.

- They are emotional intelligent people. They calculate and weigh the risks carefully.

- Knowledge workers not only share their knowledge, skills and ideas with others but also they learn from others.

- They motivate and through productivity (knowledge oriented students), quality (in terms of education), innovations and intellectual property, produce best performance for the organizational development.

- They maintain the organization as source of strategic facilitator, competitor and value creation.

- They provide the good services to the students, alumni, staff and faculty members.

- Best and foremost quality of research is delivered by knowledge workers.

\subsection{Research Issues on Using ICT for KM in Higher Education -}

There are many issues related to the research that use the ICT for improvising KM in higher education according to the evidence from the available literature. the theoretical basis for using ICT to enhance KM in higher education is still weak, and practiced- based implementations prevail, even though, many theories exist on KM. Also there are not many empirical assessments on the concerned issues that have led to huge gaps in the current body of knowledge which would help address the emerging challenges.

- $\quad$ ICT and KM processes in higher education

- ICT and KM for collaborative learning

- ICT, KM and people

- ICT, organizational strategy and higher education

- Measurement and evaluation of KM

- KM capabilities and infrastructure

\subsection{Nonaka and Takeuchi Model-}

It is appalling that despite great care being taken in the formation of knowledge and the allocation of matters and theory, the Nonaka model [16] has ignored the reusable knowledge, especially in educational environment.

Socialization: The collaboration between teachers and students, teachers and teachers and students and students is referred to as socialization that results in tacit knowledge being shared.

Externalization - A lot of extra know-how will be available at disposal to an organization in addition to having a greater confidence in such knowledge due to corrective or qualitative knowledge being created by replication.

Combination - This makes the explicit knowledge positive and the tacit knowledge negative. E.g. the documented knowledge applied by the teacher is questioned by the students or the administrative authorities in an educational institution.

Internalization - The process of accepting the information by tapping with one's own knowledge currently owned is referred to as internalization.

It is because of the conversion of knowledge from one form to another that its importance is enhanced in real educational life. As proposed by Nonaka and Takeuchi Model [17], it will be spiral. This also encompasses reusability with time. Hence, sharing of knowledge (as the time enhances), (and translation of tacit into explicit knowledge) a in an educational setting, enhances knowledge reusability.

\subsection{Questionnaire -}

The survey was taken from staff / students working in the Industry Practice Requisite and Consultancy Lab. Questionnaire was given to 80 students and staff.

\begin{tabular}{|c|l|l|l|l|l|l|}
\hline $\begin{array}{c}\text { Sr. } \\
\text { No }\end{array}$ & Questionnaire & $\begin{array}{l}\text { Strongly } \\
\text { Disagree }\end{array}$ & Disagree & Neutral & Agree & $\begin{array}{l}\text { Strongly } \\
\text { Agree }\end{array}$ \\
\hline 1 & $\begin{array}{l}\text { You start design of the project after } \\
\text { going through the Software } \\
\text { Engineering Repository }\end{array}$ & $\begin{array}{l}\text { Strongly } \\
\text { Disagree }\end{array}$ & Disagree & Neutral & Agree & $\begin{array}{l}\text { Strongly } \\
\text { Agree }\end{array}$ \\
\hline 2 & $\begin{array}{l}\text { Do you believe that Software } \\
\text { Engineering repository helps to } \\
\text { improve personal performance }\end{array}$ & $\begin{array}{l}\text { Strongly } \\
\text { Disagree }\end{array}$ & Disagree & Neutral & Agree & $\begin{array}{l}\text { Strongly } \\
\text { Agree }\end{array}$ \\
\hline 3 & $\begin{array}{l}\text { Do you always find solutions to design } \\
\text { issues in the Software Engineering } \\
\text { Repository? }\end{array}$ & $\begin{array}{l}\text { Strongly } \\
\text { Disagree }\end{array}$ & Disagree & Neutral & Agree & $\begin{array}{l}\text { Strongly } \\
\text { Agree }\end{array}$ \\
\hline
\end{tabular}




\begin{tabular}{|c|l|l|l|l|l|l|}
\hline 4 & $\begin{array}{l}\text { Are you able to complete your task } \\
\text { using the current organizational } \\
\text { structure using Software Engineering } \\
\text { knowledge management services? }\end{array}$ & $\begin{array}{l}\text { Strongly } \\
\text { Disagree }\end{array}$ & Disagree & Neutral & Agree & $\begin{array}{l}\text { Strongly } \\
\text { Agree }\end{array}$ \\
\hline 5 & $\begin{array}{l}\text { Do you attend discussion / meetings in } \\
\text { Knowledge management practices? }\end{array}$ & $\begin{array}{l}\text { Strongly } \\
\text { Disagree }\end{array}$ & Disagree & Neutral & Agree & $\begin{array}{l}\text { Strongly } \\
\text { Agree }\end{array}$ \\
\hline 6 & $\begin{array}{l}\text { Is there a free flow of ideas during your } \\
\text { knowledge management meetings? }\end{array}$ & $\begin{array}{l}\text { Strongly } \\
\text { Disagree }\end{array}$ & Disagree & Neutral & Agree & $\begin{array}{l}\text { Strongly } \\
\text { Agree }\end{array}$ \\
\hline 7 & $\begin{array}{l}\text { Can you influence the management } \\
\text { with respect to the Knowledge } \\
\text { management practices? }\end{array}$ & $\begin{array}{l}\text { Strongly } \\
\text { Disagree }\end{array}$ & Disagree & Neutral & Agree & $\begin{array}{l}\text { Strongly } \\
\text { Agree }\end{array}$ \\
\hline 8 & $\begin{array}{l}\text { Does your organization support } \\
\text { reframing Knowledge management } \\
\text { practices at the strategic level? }\end{array}$ & $\begin{array}{l}\text { Strongly } \\
\text { Disagree }\end{array}$ & Disagree & Neutral & Agree & $\begin{array}{l}\text { Strongly } \\
\text { Agree }\end{array}$ \\
\hline 9 & $\begin{array}{l}\text { Do you exchange information with } \\
\text { colleagues for solving problems? }\end{array}$ & $\begin{array}{l}\text { Strongly } \\
\text { Disagree }\end{array}$ & Disagree & Neutral & Agree & $\begin{array}{l}\text { Strongly } \\
\text { Agree }\end{array}$ \\
\hline 10 & $\begin{array}{l}\text { Overall Rating for Software } \\
\text { Engineering Management Services is } \\
\text { highly effective? }\end{array}$ & Poor & $\begin{array}{l}\text { Below } \\
\text { Average }\end{array}$ & Average & Effective & $\begin{array}{l}\text { Highly } \\
\text { effective }\end{array}$ \\
\hline
\end{tabular}

Table 1: Questionnaire

\section{ANALYSIS OUTPUT}

The answers of the questionnaire were analyzed and the results are presented in this section. The frequency table of Q1 to Q10 is presented and shows the percent, valid percent and cumulative percent.

\begin{tabular}{|c|c|c|c|c|c|}
\hline \multicolumn{2}{|c|}{ Frequency Table Q1 } & Frequency & Percent & Valid Percent & Cumulative Percent \\
\hline \multirow{5}{*}{ Valid } & Agree & 24 & 30.0 & 30.0 & 30.0 \\
\hline & Disagree & 16 & 20.0 & 20.0 & 50.0 \\
\hline & Neutral & 21 & 26.3 & 26.3 & 76.3 \\
\hline & \begin{tabular}{|l|} 
Strongly Agree \\
\end{tabular} & 19 & 23.8 & 23.8 & 100.0 \\
\hline & Total & 80 & 100.0 & 100.0 & \\
\hline \multicolumn{2}{|c|}{ Frequency Table Q2 } & Frequency & Percent & Valid Percent & Cumulative Percent \\
\hline \multirow{5}{*}{ Valid } & Agree & 22 & 27.5 & 27.5 & 27.5 \\
\hline & Disagree & 13 & 16.3 & 16.3 & 43.8 \\
\hline & Neutral & 23 & 28.8 & 28.8 & 72.5 \\
\hline & Strongly Agree & 22 & 27.5 & 27.5 & 100.0 \\
\hline & Total & 80 & 100.0 & 100.0 & \\
\hline \multicolumn{2}{|c|}{ Frequency Table Q3 } & Frequency & Percent & Valid Percent & Cumulative Percent \\
\hline \multirow{5}{*}{ Valid } & Agree & 18 & 22.5 & 22.5 & 22.5 \\
\hline & Disagree & 20 & 25.0 & 25.0 & 47.5 \\
\hline & Neutral & 19 & 23.8 & 23.8 & 71.3 \\
\hline & Strongly Agree & 23 & 28.8 & 28.8 & 100.0 \\
\hline & Total & 80 & 100.0 & 100.0 & \\
\hline \multicolumn{2}{|c|}{ Frequency Table Q4 } & Frequency & Percent & Valid Percent & Cumulative Percent \\
\hline \multirow{5}{*}{ Valid } & Agree & 24 & 30.0 & 30.0 & 30.0 \\
\hline & Disagree & 18 & 22.5 & 22.5 & 52.5 \\
\hline & Neutral & 19 & 23.8 & 23.8 & 76.3 \\
\hline & Strongly Agree & 19 & 23.8 & 23.8 & 100.0 \\
\hline & Total & 80 & 100.0 & 100.0 & \\
\hline \multicolumn{2}{|c|}{ Frequency Table Q5 } & Frequency & Percent & Valid Percent & Cumulative Percent \\
\hline \multirow{5}{*}{ Valid } & Agree & 20 & 25.0 & 25.0 & 25.0 \\
\hline & Disagree & 18 & 22.5 & 22.5 & 47.5 \\
\hline & Neutral & 21 & 26.3 & 26.3 & 73.8 \\
\hline & Strongly Agree & 21 & 26.3 & 26.3 & 100.0 \\
\hline & \begin{tabular}{|l|} 
Total \\
\end{tabular} & 80 & 100.0 & 100.0 & \\
\hline \multicolumn{2}{|c|}{ Frequency Table Q6 } & Frequency & Percent & Valid Percent & Cumulative Percent \\
\hline
\end{tabular}




\begin{tabular}{|c|c|c|c|c|c|}
\hline \multirow{5}{*}{ Valid } & Agree & 20 & 25.0 & 25.0 & 25.0 \\
\hline & Disagree & 17 & 21.3 & 21.3 & 46.3 \\
\hline & Neutral & 23 & 28.8 & 28.8 & 75.0 \\
\hline & Strongly Agree & 20 & 25.0 & 25.0 & 100.0 \\
\hline & Total & 80 & 100.0 & 100.0 & \\
\hline \multicolumn{2}{|c|}{ Frequency Table Q7 } & Frequency & Percent & Valid Percent & Cumulative Percent \\
\hline \multirow{5}{*}{ Valid } & Agree & 25 & 31.3 & 31.3 & 31.3 \\
\hline & Disagree & 14 & 17.5 & 17.5 & 48.8 \\
\hline & Neutral & 16 & 20.0 & 20.0 & 68.8 \\
\hline & Strongly Agree & 25 & 31.3 & 31.3 & 100.0 \\
\hline & Total & 80 & 100.0 & 100.0 & \\
\hline \multicolumn{2}{|c|}{ Frequency Table Q8 } & Frequency & Percent & Valid Percent & Cumulative Percent \\
\hline \multirow{5}{*}{ Valid } & Agree & 23 & 28.8 & 28.8 & 28.8 \\
\hline & Disagree & 23 & 28.8 & 28.8 & 57.5 \\
\hline & Neutral & 10 & 12.5 & 12.5 & 70.0 \\
\hline & Strongly Agree & 24 & 30.0 & 30.0 & 100.0 \\
\hline & Total & 80 & 100.0 & 100.0 & \\
\hline \multicolumn{2}{|c|}{ Frequency Table Q9 } & Frequency & Percent & Valid Percent & Cumulative Percent \\
\hline \multirow{5}{*}{ Valid } & Agree & 17 & 21.3 & 21.3 & 21.3 \\
\hline & Disagree & 23 & 28.8 & 28.8 & 50.0 \\
\hline & Neutral & 25 & 31.3 & 31.3 & 81.3 \\
\hline & Strongly Agree & 15 & 18.8 & 18.8 & 100.0 \\
\hline & Total & 80 & 100.0 & 100.0 & \\
\hline \multicolumn{2}{|c|}{ Frequency Table Q10 } & Frequency & Percent & Valid Percent & Cumulative Percent \\
\hline \multirow{4}{*}{ Valid } & Average & 54 & 67.5 & 67.5 & 67.5 \\
\hline & Effective & 21 & 26.3 & 26.3 & 93.8 \\
\hline & Highly Effective & 5 & 6.3 & 6.3 & 100.0 \\
\hline & Total & 80 & 100.0 & 100.0 & \\
\hline
\end{tabular}

Table 2: Frequency Table Q1-Q10

The percent of Q1 to Q10 are shown in the following bar charts.

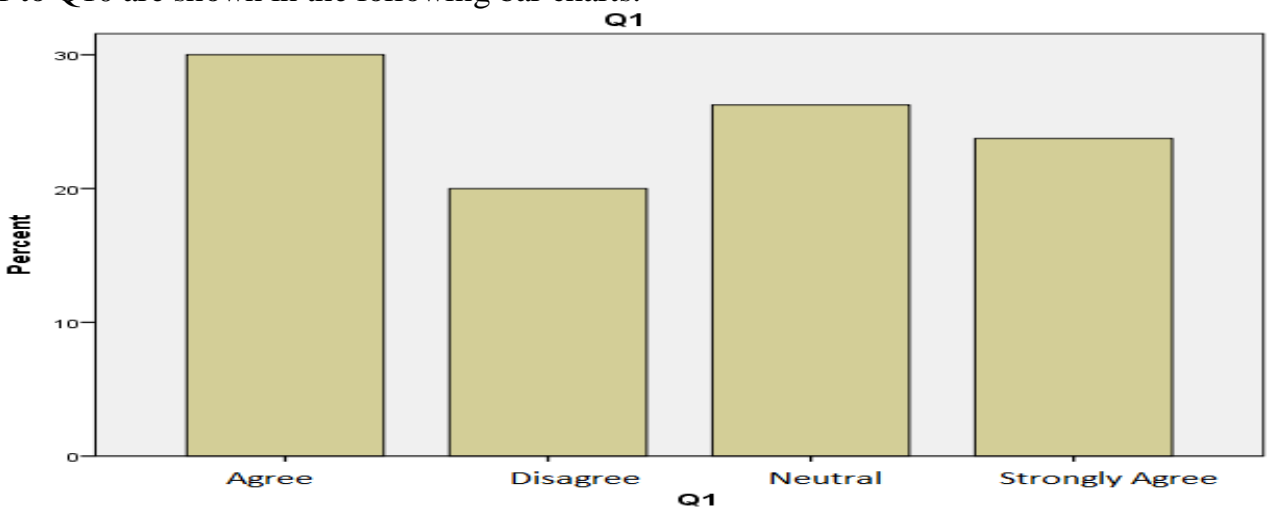

Figure 1. Frequency percent for Q1

From this Q1 figure, it can be observed that the percent of 'agree' is higher than the percent of disagree, neutral and strongly agree. 


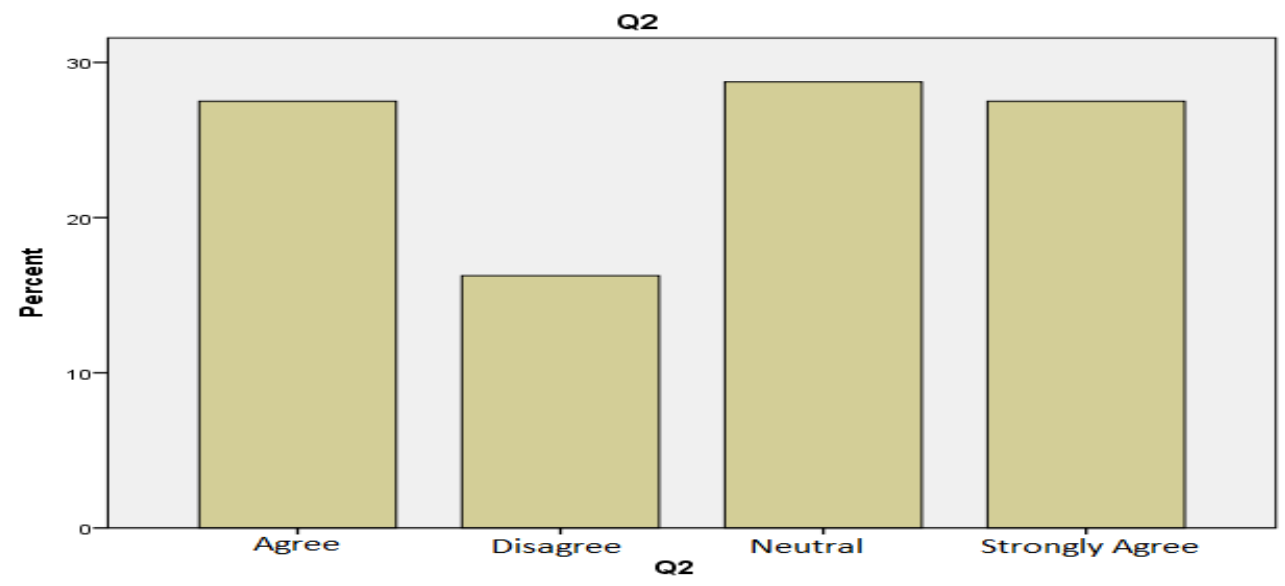

Figure 2. Frequency percent for Q2

From this Q2 figure, it can be observed that the percent of 'neutral' is higher than the percent of agree, disagree and strongly agree. The percentage of disagree is the lowest thus suggesting that software repository helps to improve personal performance.

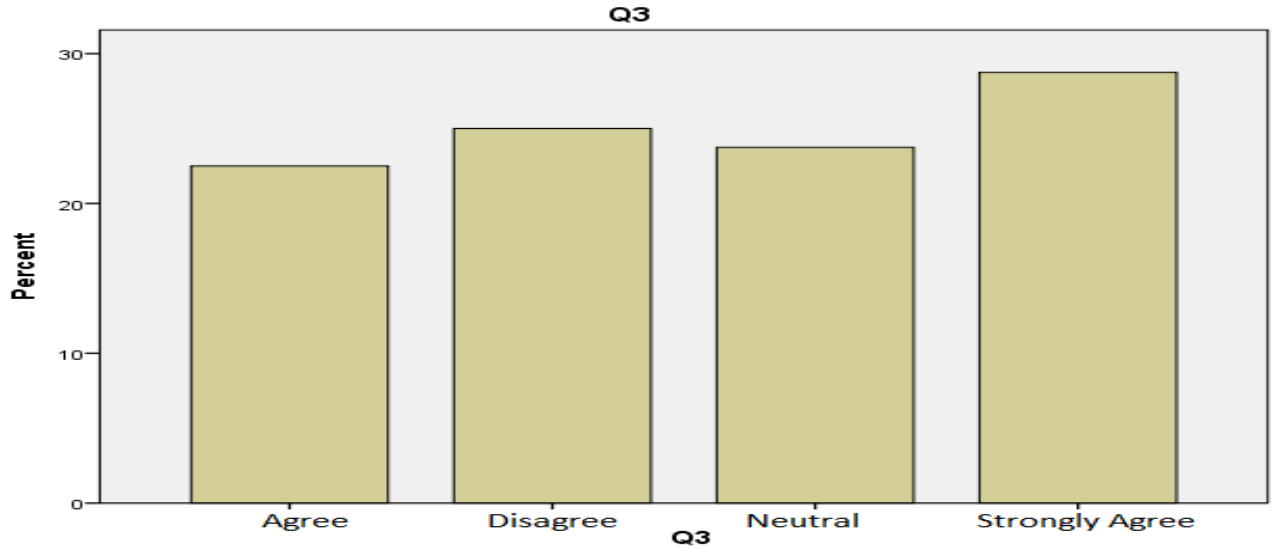

Figure 3. Frequency percent for Q3

From this Q3 figure, it can be observed that the percent of strongly agree is higher than the percent of agree, disagree and neutral.

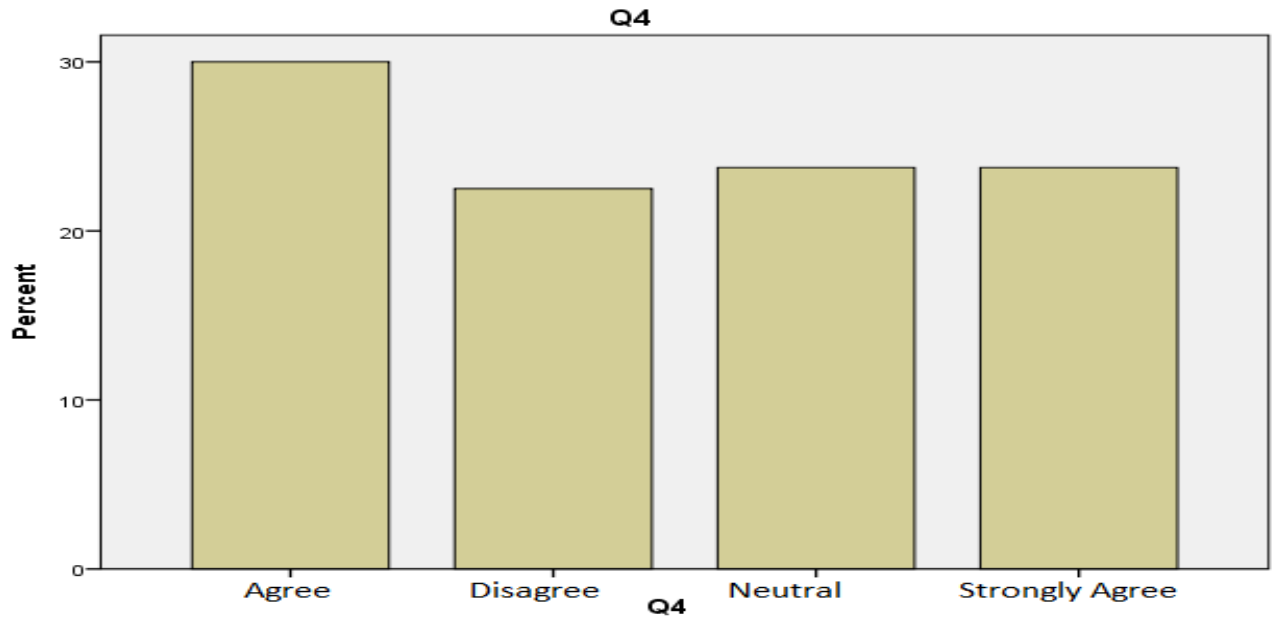

Figure 4. Frequency percent for Q4

From this Q4 figure, it can be observed that the percent of agree is higher than the percent of disagree, neutral and strongly agree. 


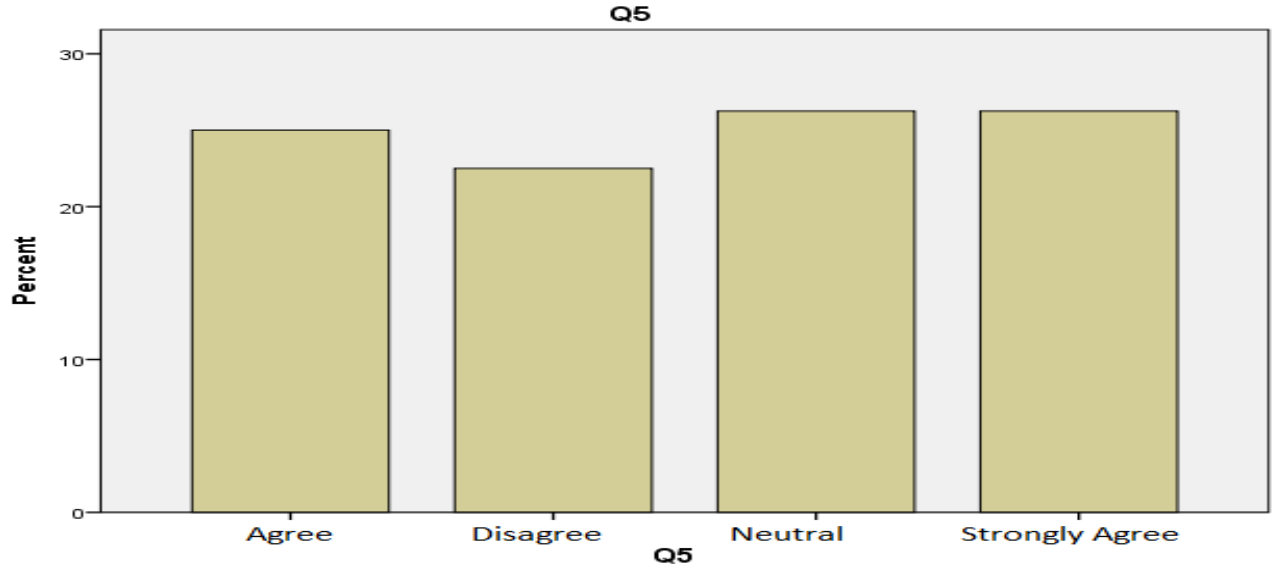

Figure 5. Frequency percent for Q5

From this Q5 figure, it can be observed that the percent of neutral and strongly agree is higher than the percent of agree and disagree.

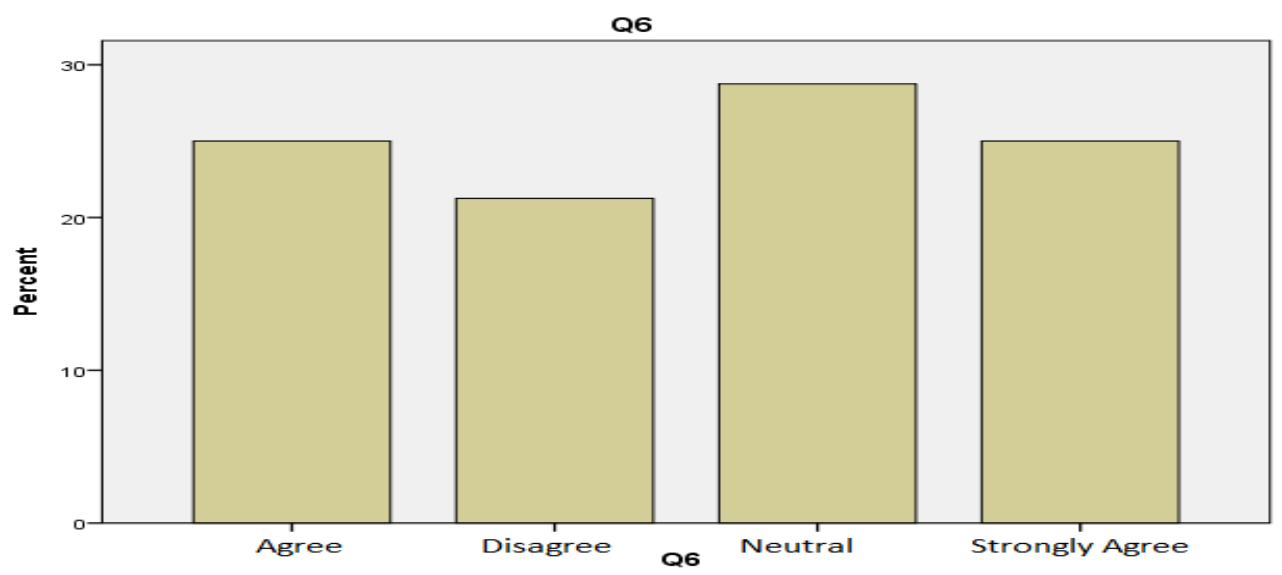

Figure 6. Frequency percent for Q6

From this Q6 figure, it can be observed that the percent of neutral is higher than the percent of agree, disagree and strongly agree.

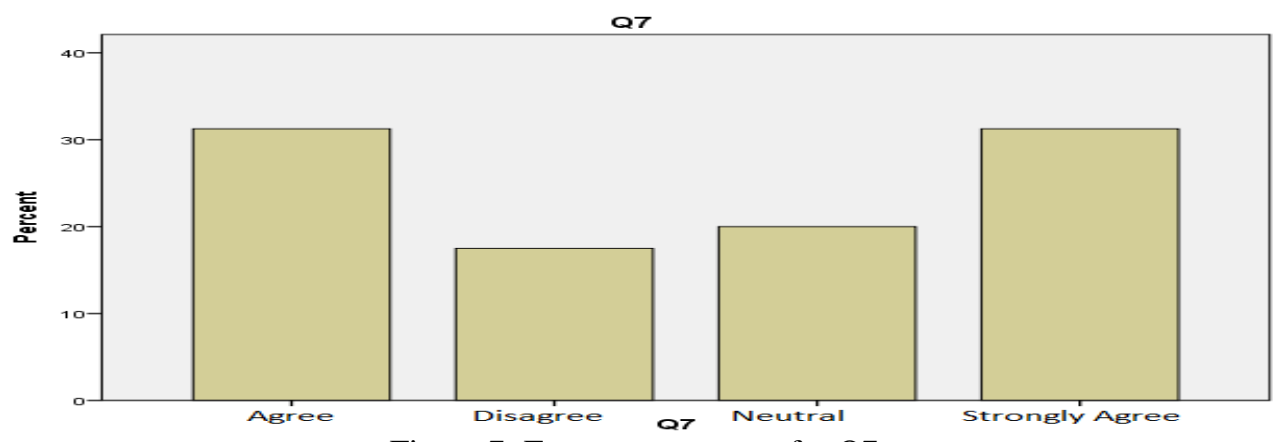

Figure 7. Frequency percent for Q7

From this Q7 figure, it can be observed that the percent of agree and strongly agree is higher than the percent of disagree and neither agree not disagree. 


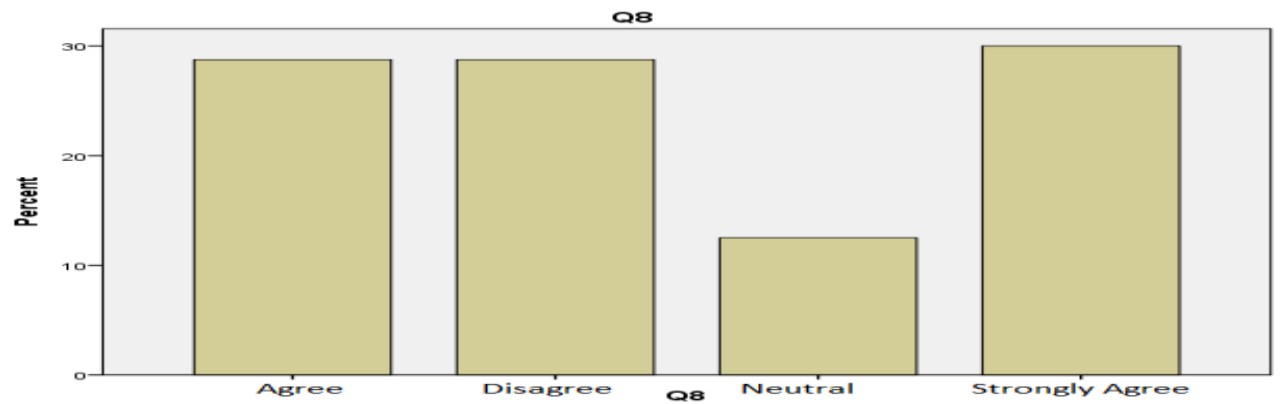

Figure 8. Frequency percent for Q8

From this Q8 figure, it can be observed that the percent of strongly agree is higher than the percent of agree, disagree and neutral.

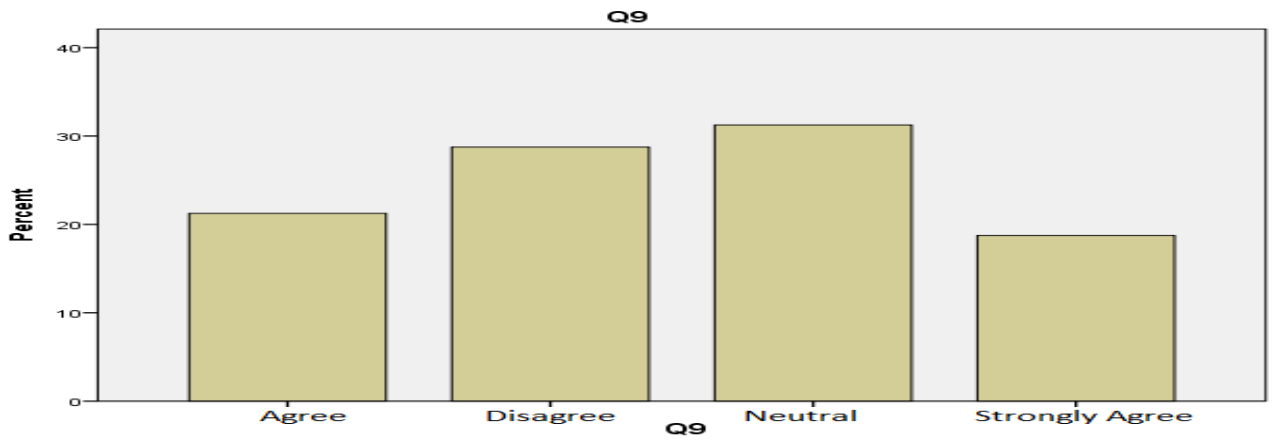

Figure 9.Frequency percent for Q9

From this Q9 figure, it can be observed that the percent of neutral is higher than the percent of agree, disagree and strongly agree.

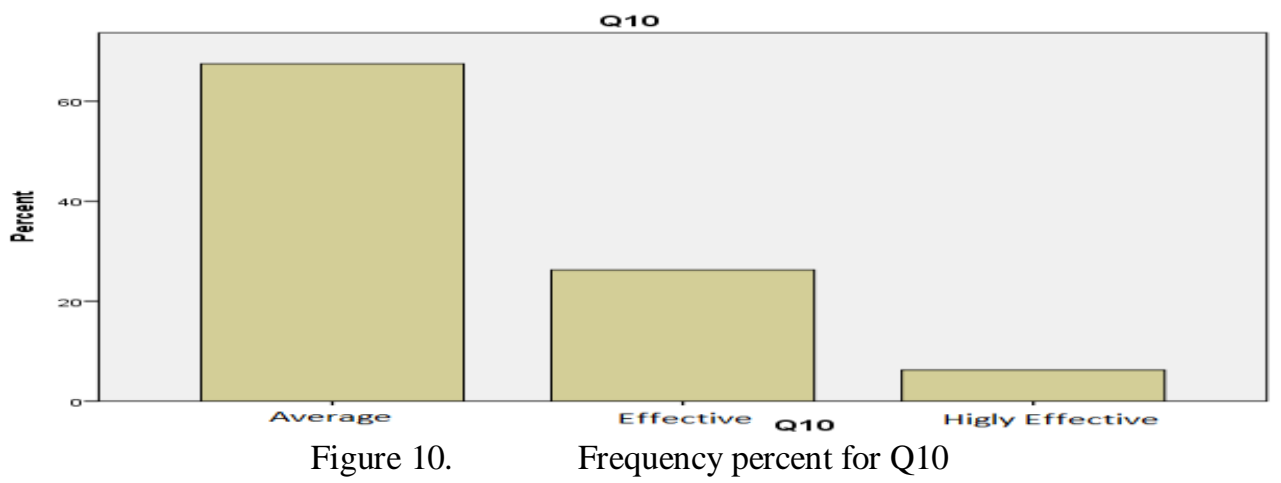

From the Q10 figure, it can be observed that the percent of average is higher than the percent of effective and highly effective.

\section{DISCUSSION:}

The questionnaire aimed to find the general feeling of the software engineering repository and its effectiveness. It is observed from the survey that most of the users do refer the software engineering repository at the start of the project, and mostly find solutions in it for their tasks. It is also seen that the users find the current organizational structure of the KM service as efficient. The gap in the structure observed is that discussions and meetings among the users are not effective and there is a break in exchange of ideas for solving problems. In conclusion, it can be stated that though the KM services are efficient, it is not being fully utilized due to communication lag among the users in the organization. Solutions to address this can be explored.

\section{CONCLUSION}

In higher education, KM is becoming a very crucial issue. This drives the collecting, analyzing, transforming of knowledge and applying the innovations. The KM systems enable fast and easy access and retrieval of knowledge. Knowledge dimensions that provide quality research based programs must be identified by higher educational systems in order to evolve students to become knowledge workers. Also, in order to sustain and grow their knowledge capital, higher educational institutions require the faculty and students to be committed to long term learning. It is imperative for higher educational systems to concentrate on strategic knowledge, procedural and enhancement of metacognitive knowledge, the understanding process, applying, 
evaluating, and creating of ideas in order to develop knowledge workers. Thus, people who possess the following qualities remain in demand forever.

\section{REFERENCES}

[1] Pinto, M. (2013). Knowledge management systems and intellectual capital measurement in Portuguese organizations: a case study. In Advances in Information Systems and Technologies (pp. 23-32). Springer Berlin Heidelberg.

[2] Evangelista, P, Esposito, E, Lauro, V \& Raffa, M (2010), "The adoption of knowledge management systems in small firms", Electronic Journal of Knowledge Management, vol. 8, no. 1, pp. 33 - 42, viewed 12 April 2010,

[3] Bhusry, M., \& Ranjan, J. (2011). Knowledge collaboration in higher educational institutions in india: Charting a knowledge management solution. International Journal of Computer Science, 8.

[4] Aggestam, L. (2006, September). Towards a maturity model for learning organizations-the role of Knowledge Management. In Database and Expert Systems Applications, 2006. DEXA'06. 17th International Workshop on (pp. 141-145). IEEE.

[5] Aggestam, L. (2015). Learning organization or knowledge management-Which came first, the chicken or the egg?. Information technology and control, 35(3).

[6] Wong, K. Y., \& Aspinwall, E. (2004). Knowledge management implementation frameworks: a review. Knowledge and Process Management, 11(2), 93-104.

[7] Laal, M. (2011). Knowledge management in higher education. Procedia Computer Science, 3, 544-549.

[8] Pinto, M. (2014, June). Knowledge management in higher education institutions: a framework to improve collaboration. In Information Systems and Technologies (CISTI), 2014 9th Iberian Conference on (pp. 1-4). IEEE.

[9] Nawaz, M. N., \& Gomes, A. M. (2014). Review of knowledge management in higher education institutions.

[10] Veisi, H. (2010). Organizational Learning in the Higher Education Institutions (A Case Study of Agricultural and Natural Recourses Campus of University of Tehran). International Online Journal of Educational Sciences, 2(1), 21-36.

[11] Omona, W., van der Weide,T., \& Lubega, J. (2010). Using ICT to enhance knowledge management in higher education: A conceptual framework and research agenda. International Journal of Education and Development using Information and Communication Technology, 6(4), 83.

[12] Khasawneh, M. M., \& Ibrahim, H. B. H. Adoption, Diffusion, Use and Impact of ICT In Developing Countries: A Case Study of Jor dan.

[13] Liao, S. H., \& Wu, C. C. (2010). System perspective of knowledge management, organizational learning, and organizational innovation. Expert systems with Applications, 37(2), 1096-1103.

[14] Namdev Dhamdhere, S. (2015). Importance of Knowledge Management in the Higher Educational Institutes. Turkish Online Journal of Distance Education, 16(1), 162-183.

[15] Kok, A (2007),"Intellectual Capital Management as Part of Knowledge management Initiatives at Institutions of Higher Learning". The Electronic Journal of Knowledge Management, Vol. 5, Issue 2, pp. 181-192.

[16] Sharma, S., \& Harsh, O. K. (2017). Role of Explicit Knowledge Management and Reuse in Higher Educational Environment. International Journal of Advanced Computer Science \& Applications, 1(8), 193-197.

[17] I. Nonaka, \& H. Takeuchi The Knowledge-Creating Company: How Japanese Companies Create the Dynamics for Innovation. Oxford University Press, New York, NY (1995). 